\title{
Plasma proteomic analysis of systemic lupus erythematosus patients using liquid chromatography/tandem mass spectrometry with label-free quantification
}

\author{
Rashmi Madda ${ }^{1}$, Shih-Chang Lin ${ }^{2,3}$, Wei-Hsin Sun ${ }^{1}$, Shir-Ly Huang ${ }^{\text {Corresp. } 4}$ \\ 1 Department of Life Sciences, National Central University, Zhongli, Taiwan \\ 3 Department of Rheumatology and Immunology, Cathay General Hospital, Taipei, Taiwan \\ 4 Institute of Microbiology and Immunology, National Yang-Ming University, Taipei, Taiwan \\ Corresponding Author: Shir-Ly Huang \\ Email address: sl.huang@ym.edu.tw
}

Context: Systemic lupus erythematosus (SLE) is a chronic inflammatory autoimmune disease with unknown etiology.

Objective: Human plasma is comprised of over ten orders of magnitude concentration of proteins and tissue leakages. The changes in the abundance of these proteins have been playing an important role in various human diseases. Therefore, the research objective of this study is to identify the significantly altered expression levels of plasma proteins from SLE patients compared with healthy controls using proteomic analysis. The plasma proteome profiles of both SLE patients and controls were compared.

Methods: 19 active SLE patients and 12 healthy controls plasma samples were analyzed using highresolution electrospray ionization liquid chromatography-tandem mass spectrometry (LC-ESI-MS/MS) followed by label-free quantification. Results: Nineteen proteins showed a significant level of expression in the comparative LC-ESI-MS/MS triplicate analysis, among these, 14 proteins with $>1.5$ to 3 fold upregulation and five with $<0.2-0.6$ fold down-regulation. GO and DAVID functional enrichment analysis revealed that these proteins involved in several important biological processes including acute phase inflammatory responses, complement activation, hemostasis, and immune system regulation.

Conclusion: Our study identified a group of differentially expressed proteins in the plasma of SLE patients that are involved in the imbalance of the immune system and inflammatory responses. Therefore, these findings may have the potential to be used as prognostic/diagnostic markers for SLE disease assessment or disease monitoring. 
$5{ }^{1}$ Department of Life Sciences, National Central University, Taiwan, ${ }^{2}$ Department of Medicine,

6 College of Medicine, Fu-Jen Catholic University, Taiwan; ${ }^{3}$ Division of Rheumatology and

7 Immunology, Cathay General Hospital, Taipei, Taiwan, ${ }^{4}$ Institute of Microbiology and Immunology,

8 National Yang-Ming University, Taipei, Taiwan

9 Running Title: Differentially regulated plasma proteins of SLE

$10 *$ Correspondence to:

11 Shir-Ly Huang,

12 Institute of Microbiology and Immunology,

13 National Yang-Ming University, Taipei, Taiwan.

14 Email: sl.huang@ym.edu.tw

15 Tel: $\underline{+886-2-2826-7108} ;$ Fax: $+\underline{886-2-2826-7000}$

16 Wei-Hsin Sun,

17 Department of Life Sciences,

18 National Central University, Taiwan

19 Email: weihsin@,cc.ncu.edu.tw

20 
Abstract

22 Context: Systemic lupus erythematosus (SLE) is a chronic inflammatory autoimmune disease with

23 unknown etiology.

24 Objective: Human plasma is comprised of over ten orders of magnitude concentration of proteins

25 and tissue leakages. The changes in the abundance of these proteins have been playing an important role in various human diseases. Therefore, the research objective of this study is to identify the significantly altered expression levels of plasma proteins from SLE patients compared with healthy controls using proteomic analysis. The plasma proteome profiles of both SLE patients and controls were compared.

Methods: 19 active SLE patients and 12 healthy controls plasma samples were analyzed using highresolution electrospray ionization liquid chromatography-tandem mass spectrometry (LC-ESIMS/MS) followed by label-free quantification.

Results: Nineteen proteins showed a significant level of expression in the comparative LC-ESIMS/MS triplicate analysis, among these, 14 proteins with $>1.5$ to 3 fold up-regulation and five with $<0.2-0.6$ fold down-regulation. GO and DAVID functional enrichment analysis revealed that these proteins involved in several important biological processes including acute phase inflammatory responses, complement activation, hemostasis, and immune system regulation.

Conclusion: Our study identified a group of differentially expressed proteins in the plasma of SLE patients that are involved in the imbalance of the immune system and inflammatory responses. Therefore, these findings may have the potential to be used as prognostic/diagnostic markers for SLE disease assessment or disease monitoring. 


\section{Introduction}

Systemic lupus erythematosus (SLE) is a chronic autoimmune disease involving multiple organs that are characterized by excessive production of antinuclear antibodies (Crispin et al., 2010). The particular reasons behind the cause of SLE have not been recognized yet, but numerous factors have been shown to be related to the development of SLE, including genetic factors, environmental triggers, hormonal imbalance and life cycle changes (Lisnevskaia et al., 2014). One of the most important mechanisms involved in the development of SLE is alterations to immune reactions; these involve auto-antibodies that target the patient's own tissues and subsequently leads to inflammation.

54 (Pisetsky et al., 1997).

Rapid advances in proteomic technology have led to the identification of several novel protein biomarkers related to both SLE and lupus nephritis (LN); these include monocyte chemoattractant protein-1 (MCP-1) (Marks et al., 2010), the tumor necrosis factor-like weak inducer (TWEAK) (Schwartz et al., 2007), transferrin (Suzuki et al., 2007), various interleukins and TNF- $\alpha$ research progress regarding biomarkers discovery, SLE remains an unsolved puzzle due to a lack of appropriate disease monitoring and the absence of predictive/diagnostic biomarkers. Thus the quest for such markers is still continuing.

Human serum/plasma holds abundant information on the physiological and pathological states of an individual's body, and as a result, such samples can provide valuable clinical parameters (Anderson et al., 2002). Consequently, they have enormous potential in terms of revealing disease conditions and they also hold the promise of a revolution in disease diagnosis and therapeutic monitoring. Moreover, plasma is a very rich source of proteins and tissue leakage with the presence of interleukins (Anderson et al., 2002). The protein alterations in a diseased plasma sample may 
70 provide clues and potential clinical parameters that should help us to understand both the

71 pathogenesis of a disease, as well as diagnosis.

Significant advances in proteomic technologies now allow the comprehensive profiling of

73 protein expression levels in biofluids from patients with a given disease (Hu et al., 2006).

74 Furthermore, mass spectrometry technologies have become a significant approach in clinical

75 proteomics which allows the exploration in depth of an illness and its underlying mechanisms. together with database searching has emerged as a robust technique that allows protein identification and characterization. Numerous studies have successfully demonstrated the utility of high-resolution electrospray ionization liquid chromatography tandem mass spectrometry (LC-ESI-MS/MS), which allows the highly sensitive identification of hundreds of distinct proteins in a given biomedical sample (Korte et al ., 2012).

Therefore, our current study incorporated LC-ESI-MS/MS label-free shotgun proteomic methodology with the aim of identifying significant changes in the expression levels of plasma proteins from SLE patients compared with healthy controls. The proteins identified as having altered expression levels may serve as potential candidate biomarkers for SLE disease assessment and monitoring of the disease progression. 


\section{Manuscript to be reviewed}

95 Materials and Methods:

\section{Collection of SLE samples and healthy control samples}

A total of nineteen SLE patients (female/male; 18/1; mean age 32.1 ranging from 22-54 years) and the same age and gender-matched twelve healthy controls (female/male; $9 / 3$; mean age 32.9 ranging from 26-54 years of age) plasma samples were obtained from the Cathay General Hospital (CGH), Taipei, Taiwan. The disease assessment of the collected SLE samples was performed according to the classification criteria of the American College of Rheumatology (Tan et al., 1982). The Systemic Lupus Erythematosus Disease Activity Index (SLEDAI) scoring method was used to determine the level of SLE disease activity (Bombardier et al., 1992). Based on the disease activity index parameter results, all of the recruited SLE patients had active disease (SLEDAI more than 8) with high titers of anti-ds DNA antibodies, and the presence of proteinuria and low levels of complement. The demographic characteristics of patients and controls are presented in Table 1. Plasma was prepared from the whole blood samples, which were collected in heparin-containing tubes from both the SLE patients and the healthy controls. All the patient samples were collected prior to the clinical treatment. The protein concentrations of the collected samples were determined by Bradford protein assay (Zor et al., 1996) and the samples were stored at $-80^{\circ} \mathrm{C}$ until further analysis. This study obtained approval from the Institutional Review Board (IRB) (Approval code CT-09905) for Research Ethics at the Cathay General Hospital, Taipei, Taiwan. Informed consent was provided by all blood donors.

\section{Depletion of high abundance serum albumin protein}

In order to identify the various low and high abundance proteins by mass-based proteomic analysis, highly abundant serum albumin was depleted from the SLE and control samples by using a dye-based proteo-prep blue albumin removal kit (Thermo Co. USA). Using the manufacturer's protocol, spin columns were suspended with slurry and centrifuged at $8,000 \mathrm{X} g$ for 10 seconds. Next, $0.1 \mathrm{ml}$ of serum samples were added to the spin columns and the columns were incubated for 
$12010 \mathrm{~min}$. Subsequently, the samples were centrifuged at $8,000 \mathrm{X} g$ for 60 seconds; this was repeated

121 twice to remove further serum albumin (Ahmed et al., 2003). The protein concentrations of the

122 depleted serum samples were determined by Bradford assay and the samples were stored at $-80^{\circ} \mathrm{C}$

123 until further analysis.

124 Protein precipitation and in-solution digestion

125 The depleted SLE and healthy plasma samples were precipitated using $100 \%$ ice-cold acetone and 126 then kept overnight at $-20^{\circ} \mathrm{C}$. Then the samples were centrifuged at $14000 \mathrm{Xg}$ for $10 \mathrm{~min}$, and the 127 pellets were dissolved in $100 \mu \mathrm{l}$ of $25 \mathrm{mM} \mathrm{NH}_{4} \mathrm{HCO}_{3}$ and $6.5 \mathrm{M}$ urea $(0.1$ to $1 \mu \mathrm{g} / \mu \mathrm{l})$; this was 128 followed by an in-solution digestion procedure used in previous studies (Ru et al., 2006). Next, the 129 protein samples were reduced with $100 \mathrm{mM} \mathrm{DTT}$ at $37^{\circ} \mathrm{C}$ for 30 to $40 \mathrm{~min}$ and alkylated with 200 $130 \mathrm{mM}$ IAA in the dark at room temperature for 25 to $35 \mathrm{~min}$. After this, the protein samples were 131 digested with sequencing grade trypsin (Promega, Madison, WI, USA) using a 50:1 ratio at $37^{\circ} \mathrm{C}$. 132 The reaction was quenched by adding $2 \mu 1$ of $50 \%$ formic acid (FA), the mixture vortexed and then 133 centrifuged in order to collect the peptides. Finally, the solution was lyophilized and desalted using a 134 C18 zip-tip procedure.

Nano UPLC and mass spectrometry conditions

ESI interface Q-TOF MS/MS was carried out at a resolution of about 10000 full-width half maximum (FWHM) performance. In order to calibrate the instrument, an external standard of lock mass BSA was continuously infused at a constant flow rate of $0.25 \mu 1 / \mathrm{min}$ using the NanoACQUITY auxiliary pump at an interval of 20 secs (lock spray frequency). The precursor mass error was less than $2 \mathrm{ppm}$ and for accuracy, the lock mass data were averaged. The acquired peptide spectra were eluted using the positive $V$ mode with a scan mass range of $50-2000 \mathrm{~m} / \mathrm{z}$ and a scan

142 time of $1 \mathrm{Sec}$. After reconstituting in 3\% ACN and $0.1 \% \mathrm{FA}$, the digested $400 \mathrm{ng}$ peptides were 143 injected into an online nano-ACQUITY, UPLC coupled Q-TOF, Synapt-HDMS mass spectrometer 144 (Waters Corporation, Milford, MA, USA). The peptides were separated using a $\mathrm{C}_{18}$ reverse phase 
column $(1.7 \mu \mathrm{m}$ x $75 \mu \mathrm{m}$ x $250 \mathrm{~mm})$ (Waters Corporation, Milford, MA, USA). The binary solvent system used consisted of $99.9 \%$ water and $0.1 \%$ FA (mobile phase A) and $99.9 \%$ ACN and $0.1 \%$

FA (mobile phase B). The peptides were initially pre-concentrated and desalted online at a flow rate of $5 \mu \mathrm{l} / \mathrm{min}$ using a $5 \mu \mathrm{m}$ symmetry $\mathrm{C}_{18}$ trapping column (internal diameter $180 \mathrm{~mm}$, length $20 \mathrm{~mm}$ ) (Waters Corporation, Milford, MA, USA) with 0.1\% FA. After injection, the peptides were eluted into the Nano-LockSpray ion source at a flow rate of $300 \mathrm{n} / \mathrm{L}$ and a gradient of $2 \%$ to $40 \%$ for 120 min. Then the column was washed and equilibrated. The digested plasma samples were run in triplicate and the data were analyzed by ProteinLynx Global Server 4.2 software (PLGS: Waters Corporation, Milford, MA, USA) [17]. Each sample was injected three times to obtain technical triplicates.

\section{Label-free quantification}

To quantify the proteins from the LC-MS/MS, a label-free quantification analysis was performed using PEAKS Studio 8.0 (Bioinformatics Solutions Inc, Waterloo, ON, USA) (Zhang et al., 2012). Independent samples from each triplicate analysis were studied and compared between patients and the controls. Total raw data files were imported and processed using the Peaks software program for the interpretation of spectra and the retention time was set from 600 to 10500 seconds. An in-house constructed Uniprot's reference database of Homo sapiens (release 03_2014) contained 20272 entries were added and combined with a decoy database (the sequences were reversed). For label-free quantification the following parameters were specified: enzymatic digestion by trypsin, with two missed cleavages; precursor mass tolerance was $10 \mathrm{ppm}$; fragment mass tolerance: $0.7 \mathrm{Da}$, minimum charge: 2 , maximum charge: 3 . the specified fixed and variable modification consisted of carbamidomethylation (Cys), oxidation (M) and deamidated (N and Q). To determine the falsepositive identification rate, the estimated spectra was used against decoy database. A false discovery rate (FDR) of $\leq 1 \%$, with a peptide score of $-10 \log p \geq 20$ was considered adequate for confident protein identification. To determine the relative protein and peptide abundance in the tested samples, 
170 peptide feature based quantification was performed. The signal intensity of a peptide is directly

171 proportional to the abundance of the peptide in the sample, therefore, the confidently identified

172 peptide features were matched and the peptide intensity differences between two samples were able

173 to be estimated. Likewise, the area under the curve of the extracted ion chromatograms (XICs) was

174 measured and compared between two analyzed runs. To get the summed cumulative peak area of the 175 protein, only unique peptides that are assigned to particular proteins were selected.

The FDR was calculated based on the target/decoy database, and the peptides with an FDR of

$177 \leq 1 \%$ were chosen as true positive hits (considering the risk of having one false positive in twenty 178 observations). By using this active feature based quantitative approach the detected peptides with $p$ 179 values $<0.05$ and 0.01 which were identified in at least three observations from the SLE samples 180 compared to control samples were considered. In order to identify the significant protein differential expressions an independent sample T-test was performed. The quantified datasets were normalized using their spectral abundance factor values (the average of the triplicate experiments) and this was used to generate a heat map showing the differentially expressed proteins between the two groups.

\section{Quantification of altered proteins by emPAI}

To acquire confident results from our proteomic study, the widely used exponentially modified protein abundance index (emPAI) was employed as an alternative method in order to quantify the differences in abundances of the identified proteins between the SLE patients and the control subjects. Numerous label-free relative quantification studies have successfully applied the formula derived for emPAI and developed by Ishihama and colleagues (Ishihama et al., 2005).

Specifically, the MASCOT database results were generated in an Excel file (composed of emPAI, protein description, peptide identifications, the charge states of the peptides, etc.), and this was uploaded to the freely accessible (http://empai.keio.ac.jp/SCV/empai form.php) web-based system for emPAI evaluation. The following parameters were specified on the emPAI website:

IPI_HUMAN database, trypsin digestion as the enzyme, carbamidomethyl (Cys) fixed modifications, 
mass range 500-3000 Da and no retention time filtering. The uploaded sample files were analyzed and the results were exported to a separate file. To estimate the protein abundances, the mean emPAI values of the triplicate MS analyses from patients and controls were calculated and Hochberg and Benjamini calculation of false discovery rate $(F D R)(p<0.05)$ was applied to correct for multiple testing errors. Protein level fold-difference was calculated from the relative means of normalized emPAI values and the fold change differences were estimated from all replicates, with the student's t-test (two-tailed, heteroscedastic) applied to the same values. A minimum of three unique peptide sequences in at least three replicates were required for quantification.

\section{Protein identification}

For the identification of proteins, the UniProtKB database (UniProt release 2015-10) and National Center for Biotechnology non-redundant (NCBInr) was used for the database search using the Mascot software (Matrix Science version 2.2 http://www.matrixscience.com) search engine. The following parameters were specified for searching altered proteins: enzymatic digestion by trypsin with two missed cleavages, followed by carbamidomethyl as fixed and oxidation (M) as variable modifications. The peptide mass tolerance was set at $50 \mathrm{ppm}$ and the MS/MS tolerance was set at 0.1 Da with an FDR of $\leq 1 \%$. Proteins identified in all three technical replicates or in at least two of the three analyses were considered to be identified and their theoretical molecular mass (MW) and isoelectric point (pI) were determined using Mascot database.

\section{Bioinformatics Analysis}

To interpret the biological processes (BP), molecular functions (MF) and cellular components (CC) of the identified proteins, the international standardized gene function classification system of gene ontology (GO) (http://www.geneontology.org/), and the DAVID (http://david.abcc.ncifcrf.gov/) (Database Annotation Visualization, and Integrated Discovery) database with for functional analysis were used (Huang et al., 2009). For the protein-protein interaction (PPI) networks among these 
219 proteins, the STRING (Search Tool for the Retrieval of Interacting Genes/Proteins, Version 9.1)

220 database at the website: http://string-db.org/ with default parameters were used.

221 Statistical Analysis

The LC-ESI-MS/MS data was measured using peptide feature based and spectral counting 223 based quantification in order to identify the differences in protein expression levels. Data are 224 expressed as the mean \pm standard deviation (SD) and differences were determined using two 225 independent sample t-test and a paired-t-test were used to determine the differentially regulated 226 proteins between SLE and healthy controls. Statistical analysis were performed using the SPSS 227 statistical package (SPSS16, SPSS Ltd., Working, and Surrey, UK) for Windows. A probability 228 value of less than 0.05 with 95 -percent confidence limit was considered as statistically significant 229 and of $p$-values $<0.01$ were considered as highly significant. 


\section{Manuscript to be reviewed}

Screening for novel protein biomarkers from human biological fluids is able to provide essential clinical information and such information needs to be revealed via a range of proteomic strategies. Here, we have attempted to use LC-ESI-MS/MS to identify proteins that show significant alterations in expression levels among 19 SLE patients compared to 12 healthy controls. In order to detect differentially expressed proteins in the individual SLE plasma samples compared to controls, the samples were analyzed in triplicates by LC-ESI-MS/MS with label-free quantitative analysis was performed using PEAKS Q 8.0 software. Apart from the use of this software, an emPAI method by Ishihama et. al was also used manually to obtain highly confident proteomic data. Both the quantitative analysis results were complimentary to each other in terms of protein abundance and the fold change. Table 2 shows the details about the number of MS/MS spectra, peptide and protein identification and quantitation of each SLE patient and healthy sample. The proteins which are identified in at least two of the three technical replicates were selected for the quantitation and statistical analysis.

A total of 122 proteins (homologs/same name proteins were eliminated) from the SLE patients were identified (Table S1 \& Table S7), and 143 proteins were identified from the healthy controls with the molecular masses ranging from 9-550 kDa and isoelectric point ranging from 3.49.0. Out of the 122 proteins, 19 were found to have significant changes in their expression levels, including 14 up-regulated and five down-regulated; all of these fulfilled the appropriate statistical criteria (either $\mathrm{p}<0.01$ or $\mathrm{p}<0.05$ ). A comparative LC-MS/MS base peak intensity (BPI) chromatograms of SLE and healthy controls were shown in Figure 1. The BPI chromatograms show the number of marked variations in the patient group than in the control group. All of the proteins were identified by the presence of more than two and up to ten unique peptides with a protein score of $>70$, and a significance score of $<20$. The complete list of identified proteins and their fold change differences with both the quantitative analysis data among SLE patients and healthy controls 
were presented in Table S2. The PEAKS Q software generated a heat map of the differentially expressed proteins by comparing the patients and controls were shown in Figure 2. The false discovery rate specified for the identified proteins was $<1 \%$. The complete comparative proteomic analysis using PEAKS 8.0 and emPAI quantitative evaluations of the up and down-regulated proteins were presented in Table 3.

\section{Protein profile of the differentially expressed proteins}

Based on the bioinformatics analysis, the identified differentially expressed proteins were found to be immunoglobulins, acute phase reactants, glycoproteins, transporters, antiproteases and binding proteins. Mounting evidence reveals that most of the identified proteins play crucial roles in immune system regulation, inflammation, and acute inflammatory responses. SLE patients were found to have a 2.8 to more than 3.5 fold increase in expression of several immunoglobulin heavy and light chains ( $\mathrm{p}<0.01)$, a 2.6 to 3.5 -fold increase in expression of acute phase proteins (APPs) (alpha-2 macroglobulin (A2M), serotransferrin (TF/TRFE), ceruloplasmin (CP), clusterin (CLU), serum albumin (ALB), and transthyretin (TTR) ( $p<0.01)$, a 2.7 to 4.0 fold increase in expression of various glycoproteins, including alpha-1-acid glycoprotein (ORM1/A1AG1), alpha-1-acid glycoprotein 2 (ORM2/A1AG2), and alpha-1-B glycoprotein (A1BG) $(\mathrm{p}<0.04)$, a 3.2 fold increase in expression of alpha-1-antichymotrypsin (A1ACT/SERPINA3) ( $<<0.01)$, alpha-1-antitrypsin (A1AT/SERPINA1) and a 1.4 to 7 fold increase in expression of hemoglobin subunit alpha-1 (HBA1), hemoglobin subunit beta (HBB), and haptoglobin (HP/HPT) $(\mathrm{p}<0.01)$. By way of contrast, the expression of clusterin (CLU), apolipoprotein A-1 (APOA1), apolipoprotein A-2 (APOA2) and transthyretin (TTHY/TTR) were significantly decreased in SLE patients by 0.2 to 0.4 fold $(\mathrm{p}<0.01)$.

\section{Functional annotation of the identified proteins}

To gain valuable insight of the identified differentially expressed proteins from our analysis the international standardized gene function classification system of GO and the DAVID database were employed. When analyzed for CC analysis by GO annotations, most of the identified 
294 differentially expressed proteins were found in the extracellular space (46\%), while others are macromolecular in nature (27\%) and yet other were found to be part of membrane complexes $(27 \%)$ (Figure 3A). As shown in Figure 3B, the BP evaluations of the GO annotations revealed that the identified proteins are largely involved in biological regulation (15.5\%), complement activation (9.5\%), negative regulation of the immune response (12.1\%), multicellular organismal processes $(14 \%)$, immune system processes $(8.6 \%)$, metabolic processes $(12.1 \%)$, the acute inflammatory response $(10.3 \%)$, and localization $(14.7 \%)$. On the other hand, when analyzed in terms of MF, the identified proteins were mostly involved in binding (41.2\%), catalytic activity $(38.2 \%)$, receptor activity (14.7\%) transporter activity (14.7\%), and serine peptidase activity (7.2\%) (Figure 3C, Table S3 \& S4). Therefore, based on the functional analysis, the identified proteins seem to primarily play important roles in immune system regulation $(\mathrm{p}=0.001)$, in complement system activation $(\mathrm{p}=0.01)$, in the innate and adaptive immune system responses $(\mathrm{p}=0.003)$ and, potentially, in the acute inflammatory response $(\mathrm{p}=0.002)$.

According to KEGG pathway annotation, the identified protein cohort was classified into more than twenty-five pathways (Table S5 and S6) with the top eighteen of them being shown in Figure 4. Among 19 identified differentially expressed proteins, 9 proteins (A2M, A1AT, A1ACT, CLU, KV105, KV315, IGG4, SERPING1, TF) were involved in complement and coagulation pathway, 12 proteins (A1AT, A1BG, HBB, TRFE, APOA1, AACT KV315, CLUS, KV105, A2MG, APOB, A1AG2) were involved in homeostasis and immune system processes $(p=8.8 \times 10-8)$. In addition to the above findings, the majority of them were involved in a number of potentially interesting pathways such as scavenging heme from plasma, platelet activation, acute-phase responses, degranulation, signaling, aggregation, and the creation of $\mathrm{C} 4$ and $\mathrm{C} 2$ activators, etc. These pathways are highly relevant to the present study since SLE is an autoimmune disease caused by abnormalities that affect the immune system and in turn cause an acute inflammatory response. 
318 Therefore, the identified proteins are likely to play a significant role in SLE disease development

319 and/or pathogenesis.

Additionally, the STRING protein-protein interaction (PPI) network analysis demonstrated a

321 tight protein-protein interaction network when the medium PPI confidence score of 0.4 was applied

322 in STRING database, whereas at the high confidence score of 0.7 a significant association of PPT

323 networks was identified among the differentially expressed proteins as shown in Figure 5. This PPI

324 network suggests that the identified proteins have strong interactions with the proteins that contribute

325 to numerous biological processes and have a wide range of molecular functions. 


\section{Discussion}

Our comparative mass-based proteomic analysis investigated the proteomic profiles of SLE plasma samples were compared with healthy controls using the LC-ESI-MS/MS technique with label-free quantification. We were able to identify 122 differentially expressed proteins, and among these 19 proteins showed significant changes in expression with 14 of these being up-regulated and 5 being down-regulated in the SLE samples. When these proteins were subjected to the functional analysis, this protein profile was predominantly enriched with biological regulation, catalytic, and binding activity. Based on the KEGG pathway analysis most of the identified proteins particularly (A2M, A1AT, A1ACT, CLU, KV105, KV315, IGG4, SERPING1, and TF) significantly involved in complement coagulation cascades, regulation of innate and adaptive immune systems, inflammatory responses, platelet activation, and transportation of small molecules.

A set of nine acute phase proteins (APPs) were up-regulated (A2M, A1AG, ORM1, A1AT, A1ACT, CP, APOB, HP TF) and two were down-regulated (APOA1, APOA2) in our analysis. These proteins were predominantly responsible for acute phase reactions including inflammation and dysregulation of the immune system (Simon et al., 2013). In addition to this, APPs also play active roles in various physiological and pathological activities related to disease exacerbation (Simon et al., 2013). It seems likely that the identified some of the identified APPs (A2M, A1AT and A1ACT) play an important role in the complement and coagulation cascades which is an important pathway that plays a crucial role in SLE pathogenesis. Therefore, these proteins may be able to help our understanding of the mechanisms of immune reactions and inflammatory responses involved in SLE. $\mathrm{A} 2 \mathrm{M}$ protein has been previously found to be involved in a number of different diseases, including nephrotic syndrome, diabetes, and liver cirrhosis (der Velden et al., 1998). This is the first time we are reporting the higher abundance of A2M were identified in SLE patients compared to healthy individuals. In addition to these, several immunoglobulins heavy, and light chains were also 
364 found to be up-regulated in this study, and these changes illustrate that there is an imbalance in the

365 immune system and homeostasis during SLE.

366 APOB have been shown to play a significant role in immune system regulation and

367 inflammation. It was previously identified in the lupus patients with cardiovascular diseases and

368 myocardial infarction, along with changes in low and high-density lipoproteins (LDL, HDL) (Bots et

369 al., 2016). Our study also identified consistently up-regulated APOB expressions in SLE. We believe

370 that this is the first report that shows increased expressions of APOB protein in SLE patients without

371 any cardiac complications

372 The AAP proteins which are down-regulated in this study are APOA1 and APOA2, these are

373 major constituents of the high-density lipoprotein (HDL) complex, which has a specific role in lipid

374 metabolism and has anti-inflammatory properties during both acute and chronic inflammation.

375 Moreover, these are known to be immune regulators and suppress the generation of pro-

376 inflammatory cytokines by activated T-cells (Barry et al., 2004) have been demonstrated in various

377 autoimmune diseases. Furthermore, previous proteomic studies of RA and SLE have reported down-

378 regulated APOA1 expressions may responsible for the active phase of the disease. These proteins

379 also seem to have a key role in anti-inflammation (Abe et al., 2001; Kazemipour et al., 2015). Our

380 results on APOA1 expression levels agree with the previous studies and seem to confirm the active

381 SLE disease state of the patients used in this study.

382 A great deal of evidence has demonstrated that extreme oxidative stress leads to severe

383 inflammation. Moreover, SLE is known to cause severe persistent inflammation in many major

384 organs of the body. If we examine earlier SLE proteomic studies, some of the identified protein

385 expressions by this study are consistent with previous reports, examples being ORM1/A1AG, TF,

386 and CP, all of which have been detected in urine and renal biopsy samples obtained from SLE

387 samples and were reported to act as biomarkers for class IV LN (Brunner et al., 2012; Alaiya et al., 
2015; Suzuki et al., 2007). Our study identified the similar changes in expression of these proteins in our plasma SLE samples.

In addition to these, it has been shown that increased expression of SERPINA3/A1ACT and A1AT/SERPINA1 seems to play an important role in moderating inflammatory responses, and reducing the production of inflammatory mediators and the blockage of inflammatory cells.

Aggarwal et al. recently reported the increased expressions of SERPINA3/A1ACT in lupus nephritis patients and demonstrated $\mathrm{A} 1 \mathrm{ACT}$ as the best marker to differentiate active renal lupus patients from active non-renal patients (Aggarwal et al., 2017). Thus, the identified differentially regulated antiprotease class of proteins may be relevant to renal dysregulation and inflammation in active lupus patients.

HP is also involved in immune system regulation, homeostasis, and tissue repair. It has been shown to be responsible for transporting hemoglobin, inhibiting iron loss and preventing kidney damage when hemolysis is occurring (Galicia et al., 2011). Another study found higher expression of HP in SLE patients may contribute to hypergammaglobulinemia, systemic vasculitis and cardiovascular disorders (Pavon et al., 2006). Therefore, the observed HP changes from this study is consistent with the findings of the previous study and suggests that the increased HP expressions may cause severe clinical manifestations in SLE.

Two hemoglobin scavenger proteins such as HBB and HPX showed differential regulations from our findings were implicated with HDL and influence the inflammatory properties of HDL and scavenging of oxygen binding and transport from the lungs to the peripheral tissues and also involved in a number of inflammatory diseases (Newkirk et al., 1999). In addition, the depletion of HPX levels implicated in a number of inflammatory diseases such as septic shock and experimental autoimmune encephalomyelitis (Mehta et al., 2015). The primary function of HPX is heme scavenging and it protects against oxidative stress and related inflammatory diseases. Moreover, the precise role of these proteins in SLE is not recognized yet, to the best of our knowledge this is first 
413 plasma proteomic study reporting the down-regulated expressions of HPX and up-regulated HBB in

414 lupus patients.

415 The two more down-regulated proteins from our analysis are CLU, TTR/TTHY which are also

416 potentially associated with SLE pathogenesis. These play crucial roles in immune system

417 dysregulation and are associated with alterations in inflammatory reactions. CLU is a glycoprotein

418 with ubiquitous tissue distribution that has been reported to be implicated in several physiological

419 processes. Earlier evidence has shown that lower levels of CLU/apoJ are associated with some

420 feature of SLE such as a diminished control of antibody-mediated inflammation at the sites of

421 apoptosis where auto-antigens are exposed (Andrade et al., 2000). Moreover, CLU may have a

422 protective role against SLE disease activity because disturbances in apoptosis and complement

423 function seem to play essential roles in SLE pathogenesis (Burger et al., 2002). The down-regulated

424 expression level of CLU in SLE patients identified by our analysis might be associated with the fact

425 that the patients studied had active disease. Therefore, the above findings on CLU expression levels

426 among SLE patients suggest that this protein is likely to be an important biomarker with respect to

427 SLE disease activity.

Another down-regulated protein identified is TTR, which is a serum and cerebrospinal fluid transporter of the thyroid hormone thyroxine (T4), and of retinol (Zheng et al., 2001). Earlier proteomic observations by Rana et al showed the increased expression of TTR in serum obtained

431 from pediatric SLE patients compared to controls (Rana et al., 2012). In our proteomic study, we 432 have identified TTR reduced expressions in adult SLE patients. 


\section{Conclusion:}

Taking the above as a whole, we have demonstrated that the identification of a single protein

440 that possesses exclusive characteristics of an SLE marker is indeed very challenging. The

441 identification of differential expressions of proteins in the plasma between SLE patients and controls 442 will help to develop novel approaches for the early disease detection, prevention, and the treatment 443 of SLE. Our findings have revealed that a number of proteins show changes in expression associated 444 with the presence of SLE. Moreover, some of the identified proteins and their expressions from this 445 study support the findings of previous studies. Additionally, our findings may play a significant role 446 in inflammation, acute phase responses, disease activity and immune dysregulation when SLE is 447 present. Nevertheless, these interesting findings would require subsequent investigation to validate 448 and confirm. Finally, LC-MS/MS combination with label-free quantification is clearly an excellent 449 technique for the profiling of differentially regulated proteins in the disease samples.

\section{Acknowledgements}

451 We would like to thank Cathay General Hospital (CGH) for providing the SLE and healthy plasma 452 samples for our proteomic analysis. 


\section{Manuscript to be reviewed}

\section{References}

464 1. Abe H, Tsuboi N, Suzuki S, and Sakuraba H (2001). Anti-apolipoprotein A-I autoantibody:

465 characterization of monoclonal autoantibodies from patients with systemic lupus erythematosus.

$466 \quad$ Rheumatology 28:990-95.

467 2. Ahmed N, Barker G, Oliva K, Garfin D, Talmadge K, Georgiou H, Quinn, M. and Rice, G 468 (2003). An approach to remove albumin for the proteomic analysis of low abundance biomarkers $469 \quad$ in human serum. Proteomics 3:1980-1987.

470

3. Alaiya A, Assad L, Alkhafaji D, Shinwari Z, Almana H, Shoukri M, Alkorbi L, Ibrahim HG, Abdelsalam MS, Skolnik E, Adra C, Albaqumi M (2015). Proteomic analysis of Class IV lupus nephritis. Nephrol. Dial. Transplant 30:62-70.

4. Almoallim H, Al-Ghamdi Y, Almaghrabi H, and Alyasi O. (2012). Anti-Tumor Necrosis Factor$\alpha$ Induced Systemic Lupus Erythematosus. Open Rheumatol J 6:315-319.

5. Anderson NL and Anderson NG (2002). The Human Plasma Proteome: History, Character, and Diagnostic Prospects. MCP 1:845-867.

6. Andrade F, Casciola-Rosen L, and Rosen A. (2000). Apoptosis in systemic lupus erythematosus. Clinical implications. Rheum Dis Clin North Am 26:215-27.

7. Barry B, Martina G, Oliver FG, and Jean MD. (2004). Apolipoprotein A-I infiltration in rheumatoid arthritis synovial tissue: a control mechanism of cytokine production. Arthritis Res Ther 6:563-66.

8. Bombardier C, Gladman DD, Urowitz MB, Caron D, and Chang CH. (1992). Derivation of the SLEDAI. A disease activity index for lupus patients. The Committee on Prognosis Studies in SLE. Arthritis Rheum 35:630-640.

9. Bots SH, van der Graaf Y, Nathoe HMW, de Borst GJ, Kappelle JL, Visseren FLJ, Westerink J (2016). The influence of baseline risk on the relation between HbA1c and risk for new 
cardiovascular events and mortality in patients with type 2 diabetes and symptomatic cardiovascular disease. Cardiovasc Diabetol 15:101.

10. Brunner H, Bennett M, Mina R, Suzuki M, Petri M and Kiani A. (2012). Association of noninvasively measured renal protein biomarkers with histologic features of lupus nephritis. Arthritis Rheum 64:2687-2697

11. Burger D, and Dayer JM. (2012). High-density lipoprotein-associated apolipoprotein A-I: the missing link between infection and chronic inflammation. Autoimmun Rev 1:111-117.

12. Crispín, J. C., Liossis, S.-N. C., Kis-Toth, K., Lieberman, L. A., Kyttaris, V. C., Juang, Y.-T., \& Tsokos, G. C. (2010). Pathogenesis of human systemic lupus erythematosus: recent advances. Trends in Molecular Medicine, 16(2), 47-57.

13. der Velden MGM, de Sain-van V, Rabelink TJ, Reijngoud DJ, Gadellaa MM, Voorbij H AM, Stellaard F, Kaysen GA. (1998) Plasma $\alpha 2$ macroglobulin is increased in nephrotic patients as a result of increased synthesis alone. Kidney Int 54: $530-535$.

14. Galicia G, and Ceuppens JL. (2011) Haptoglobin function and regulation in autoimmune diseases. Acute phase proteins - regulation and functions of acute phase proteins. InTech open access publisher.

15. Hu S. Loo JA, and Wong DT. (2006). Human body fluid proteome analysis. Proteomics 6: 63266353.

16. Huang da W, Sherman BT, and Lempicki RA. (2009). Systematic and integrative analysis of large gene lists using david bioinformatics resources. Nat Protoc 4:44-57.

17. Aggarwal, A., Gupta, R., Negi, V. S., Rajasekhar, L., Misra, R., Singh, P., Chaturvedi, V. and Sinha, S. (2017), Urinary haptoglobin, alpha-1 anti-chymotrypsin and retinol binding protein identified by proteomics as potential biomarkers for lupus nephritis. Clin Exp Immunol, 188: $254-262$. 
511 18. Ishihama Y, Oda Y, Tabata T, Sato T, Nagasu T, Rappsilber J, Matthias M. (2005) Exponentially

512 Modified Protein Abundance Index (emPAI) for Estimation of Absolute Protein Amount in

513 Proteomics by the Number of Sequenced Peptides per Protein. MCP 4:1265-1272.

514 19. Kazemipour, N, Qazizadeh, H, Sepehrimanesh, M, and Salimi S. (2015) Biomarkers identified 515 from serum proteomic analysis for the differential diagnosis of systemic lupus erythematosus. $516 \quad$ Lupus 24:582-87.

20. Korte EA, Gaffney PM and Powell WD. (2012). Contribution of mass spectrometry-based proteomics to defining cellular mechanisms and diagnostic markers for systemic lupus erythematosus. Arthritis Res Ther 14:204-214.

21. Lisnevskaia L, Murphy G, Isenberg D. (2014) Systemic lupus erythematosus. Lancet 384: 187888.

22. Marks SD, Shah V, Pilkington C, and Tullus K. (2010). Urinary monocyte chemoattractant protein-1 correlates with disease activity in lupus nephritis. Pediatr Nephrol 25:2283-2288.

23. Mehta NU, Reddy ST. (2015). Role of hemoglobin/heme scavenger protein hemopexin in atherosclerosis and inflammatory diseases. Curr Opin Lipidol 26:384-387.

24. Newkirk MM, Apostolakos P, Neville C, and Fortin PR. (1999). Systemic lupus erythematosus, a disease associated with low levels of clusterin/apoJ, an anti-inflammatory protein. J Rheumatol 26: 597-603.

25. Pavón, E. J., Muñoz, P., Lario, A., Longobardo, V., Carrascal, M., Abián, J., Martin, A. B., Arias, S. A., Callejas-Rubio, J.-L., Sola, R., Navarro-Pelayo, F., Raya-Alvarez, E., OrtegoCenteno, N., Zubiaur, M. and Sancho, J. (2006), Proteomic analysis of plasma from patients with systemic lupus erythematosus: Increased presence of haptoglobin $\alpha 2$ polypeptide chains over the a1 isoforms. Proteomics, 6: S282-S292. 
26. Pisetsky DS. (1997). Systemic lupus erythematosus. A. Epidemiology, pathology and pathogenesis. In: Klippel JH, ed. Primer on the rheumatic diseases, 11th ed. Georgia, USA.

27. Ru QC, Zhu LA, Katenhusen RA, Silberman J, Brzeski H, Liebman M, Shriver CD. (2006). Exploring human plasma proteome strategies: High efficiency in-solution digestion protocol for multi-dimensional protein identification technology. J Chromatogr A 1111:175-191.

28. Simon JD. (2013). Inflammation and Acute Phase Proteins in Hemostasis, Acute Phase Proteins, Prof. Sabina Janciauskiene ed, InTech 10, 5772-55998.

29. Schwartz N, Michaelson J and Putterman C. (2007). Lipocalin-2, TWEAK, and other cytokines as urinary biomarkers for lupus nephritis. Ann N. Y. Acad Sci 1109: 265-274.

30. Smržová A, Horák P, Skácelová M, Žurek M, Fryšáková L, Vymětal J, Vaverkova H. (2014). Cardiovascular events in patients with systemic lupus erythematosus. In Cor et Vasa 56:e145e152.

31. Suzuki M, Ross GF, Wiers K, Nelson S, Bennett M, Passo MH, Devarajan P, Brunner HI. (2007). Identification of a urinary proteomic signature for lupus nephritis in children. Pediatr Nephrol 22:2047-2057.

32. Tan EM, Cohen AS, Fries JF, Masi AT, Mcshane DJ, Rothfield NF, Schaller JG, Talal N, Winchester RJ. (1982). The 1982 revised criteria for the classification of systemic lupus erythematosus. Arthritis Rheum 25:1271-1277.

33. Zor T, and Selinger Z. (1996). Linearization of the Bradford Protein Assay Increases Its Sensitivity: Theoretical and Experimental Studies. Anal Biochem 236:302-308.

34. Zhang J, Xin L, Shan B, Chen W. Xie M, Yuen D, Zhang W, Zhang Z, Lajoie GA, Ma B. (2012). PEAKS DB: de novo sequencing assisted database search for sensitive and accurate peptide identification. MCP 11:M111.010587. 
557 35. Zheng W, Lu YM, Lu GY, Zhao Q, Cheung O, Blaner WS. (2001). Transthyretin, thyroxine, and

558 retinol-binding protein in human cerebrospinal fluid: effect of lead exposure. Toxicol Sci 61:

$559 \quad 107-14$

560 Abbreviations:

561 SLE: Systemic Lupus Erythematosus

562 LN: Lupus Nephritis

563 LC-ESI-MS/MS: Liquid Chromatography electrospray ionization tandem mass spectrometry

564 EmPAI: Exponentially modified protein abundance index

565 BPC: Base peak chromatogram

566 XICs: Extracted ion chromatograms

567 AUC: Area under the curve

568 A2M: Alpha 2 macroglobulin

569 TTR/TTHY: Transthyretin

570 HPT/HP: Haptoglobin

571 APOB: Apolipoprotein B-100

572 GO: Gene Ontology

573 KEGG: Kyoto encyclopedia of genes and genomics

574 DAVID: Database Annotation Visualization, and Integrated Discovery

575 STRING: Search Tool for the Retrieval of Interacting Genes/Proteins, Version 9.1

576 PPI: Protein-protein interaction networks

577 APPs: Acute phase proteins

578 CC: Cellular Components

579 MF: Molecular Function

580 BP: Biological Process 
Figure Legends:

Figure 1: A representative LC-MS/MS base peak chromatograms A) SLE patients compared to B) healthy controls.

Figure 2: An overview of the plasma protein profile of the SLE patients. The heat map was generated using PEAKS Studio 8.0 displaying the differentially expressed proteins identified using LC-MS/MS label-free proteomic analysis between SLE patients and controls. The color scale representing the relative expression level of each protein across SLE and controls; red and green color indicate the higher and lower levels of expressions. The intensity of the color represents the degree of protein up and down-regulation, when SLE patients and controls are compared.

Figure 3: Gene Ontology (GO) enrichment analysis of the differentially expressed proteins. A) Cellular component analysis of the identified proteins. B) Biological function. C) Molecular function of the identified proteins. The pie charts were generated using Panther version 11.0 released 201607-15.

Figure 4: Kyoto encyclopedia of genes and genomes (KEGG) pathway analysis of the proteins identified as showing differential expression. The majority of the identified proteins were enriched in relation to the complement and coagulation cascades and acute immune responses. The horizontal bars represent the number of differentially expressed proteins involved in various pathways.

Figure 5: The protein-protein interactions for the differentially expressed proteins identified by LCMS/MS label-free proteomics were analyzed using STRING softwareV9.1. In the network analysis the differentially expressed proteins were represented as nodes. Each color of the lines connecting the nodes indicates strong evidence of the tight network of proteins. A) The tight protein-protein interaction network obtained when the medium confidence level of 0.4 was applied. B) The high confidence (0.7) PPI network of the identified significant proteins in SLE. 


\section{Supplemental Information}

Table S1: A complete list of identified proteins in the plasma samples of SLE Patients during triplicate analysis

Table S2: A complete list of differentially expressed significant proteins identified in the SLE Patients samples compared to healthy controls

Table S3: Gene ontology biological process (BP) data for all the identified proteins from SLE patients

Table S4: Gene ontology molecular function (MF) data for all the identified proteins from SLE patients

Table S5: DAVID and Gene Ontology pathway analysis data of the identified proteins from SLE patients

Table S6: DAVID and Gene Ontology KEGG pathway analysis data of the identified proteins from SLE patients

Table S7: A representative LC-MS/MS proteomic analysis report of SLE patient's complete list of identified proteins compared to healthy controls 


\section{Table $\mathbf{1}$ (on next page)}

General and demographic characteristics of the collected SLE patients and healthy controls plasma samples

N/A: Not applicable, a: Data are represented as mean \pm standard deviation 


\begin{tabular}{lcc}
\hline & SLE patients & Healthy Individuals \\
\hline Number of samples & 19 & 12 \\
Female: male (\% female) & $18: 1(94.7 \%)$ & $9: 3(75 \%)$ \\
Age (Years) & $32.1 \pm 1.5^{\mathrm{a}}$ & $32.9 \pm 2.1^{\mathrm{a}}$ \\
SLEDAI Score (Average) & $8.47 \pm 2.8^{\mathrm{a}}$ & N/A
\end{tabular}

Anti-ds DNA antibodies

$\begin{array}{lcc}<30(\mathrm{n}=19) & 2(10.52 \%) & \text { N/A } \\ 30 \text { to }<60(\mathrm{n}=19) & 2(10.52 \%) & \text { N/A } \\ 60-200(\mathrm{n}=19) & 7(36.8 \%) & \text { N/A } \\ >200(\mathrm{n}=19) & 8(42.1 \%) & \text { N/A } \\ & & \text { N/A }\end{array}$

Anti-nuclear antibodies (ANA) $\quad \geq 1: 640$ 


\section{Table 2 (on next page)}

The complete LC-MS/MS proteomic analysis details about peptide and protein identification and quantitation in each of the patient and healthy sample. 


\begin{tabular}{|c|c|c|c|c|}
\hline SLE Patients & Total Spectra* & $\begin{array}{c}\text { Distinct } \\
\text { Peptides* }\end{array}$ & FDR Spectra & FDR Distinct peptide (\%) \\
\hline $\mathrm{P} 1$ & 169115 & 38918 & 0.41 & 1.21 \\
\hline $\mathrm{P} 2$ & 176318 & 46186 & 0.43 & 1.24 \\
\hline P3 & 165812 & 35981 & 0.47 & 1.29 \\
\hline $\mathrm{P} 4$ & 126050 & 38843 & 0.45 & 1.34 \\
\hline P5 & 169295 & 37918 & 0.41 & 1.49 \\
\hline P6 & 173378 & 36186 & 0.43 & 1.26 \\
\hline P7 & 165812 & 39991 & 0.44 & 1.25 \\
\hline P8 & 126050 & 28843 & 0.42 & 1.26 \\
\hline P9 & 149295 & 37918 & 0.42 & 1.27 \\
\hline $\mathrm{P} 10$ & 173378 & 36186 & 0.43 & 1.28 \\
\hline $\mathrm{P} 11$ & 161812 & 35881 & 0.45 & 1.44 \\
\hline $\mathrm{P} 12$ & 126050 & 28843 & 0.44 & 1.33 \\
\hline P13 & 169295 & 37918 & 0.43 & 1.35 \\
\hline P14 & 183878 & 38186 & 0.42 & 1.26 \\
\hline P15 & 165812 & 35981 & 0.45 & 1.24 \\
\hline P16 & 136050 & 28843 & 0.45 & 1.27 \\
\hline P17 & 169295 & 47918 & 0.45 & 1.25 \\
\hline P18 & 173378 & 36186 & 0.43 & 1.26 \\
\hline P19 & 165812 & 45981 & 0.42 & 1.33 \\
\hline Overall & 3045885 & 712707 & 8.25 & 24.62 \\
\hline Healthy Controls & Total Spectra & Distict Peptides & FDR Spectra & FDR Distinct peptide (\%) \\
\hline $\mathrm{H} 1$ & 138215 & 48118 & 0.31 & 1.24 \\
\hline $\mathrm{H} 2$ & 196228 & 56286 & 0.43 & 1.23 \\
\hline $\mathrm{H} 3$ & 195912 & 65181 & 0.47 & 1.31 \\
\hline $\mathrm{H} 4$ & 177050 & 47143 & 0.44 & 1.34 \\
\hline H5 & 199295 & 57928 & 0.38 & 1.39 \\
\hline $\mathrm{H} 6$ & 189378 & 39196 & 0.41 & 1.22 \\
\hline $\mathrm{H} 7$ & 165912 & 41991 & 0.41 & 1.24 \\
\hline $\mathrm{H} 8$ & 177550 & 39823 & 0.38 & 1.24 \\
\hline $\mathrm{H} 9$ & 159295 & 39938 & 0.41 & 1.27 \\
\hline $\mathrm{H} 10$ & 193378 & 39186 & 0.44 & 1.28 \\
\hline $\mathrm{H} 11$ & 181702 & 38981 & 0.45 & 1.44 \\
\hline $\mathrm{H} 12$ & 152080 & 38643 & 0.41 & 1.33 \\
\hline Overall & 2125995 & 552414 & 4.94 & 15.53 \\
\hline
\end{tabular}




\section{Table 3 (on next page)}

The list of statistically significantly up and down-regulated proteins $(p<0.05,0.01)$ between SLE patients and healthy control plasma samples. The protein abundance differences among two groups were quantified using students t-test.

A: Uniprot data entry; b Mascot protein score revealed by MudPIT scoring. The integrated mascot database batch search of all MS/MS in Swissprot v 51.6 resulted in the identification of the proteins with changed levels of expression. All the identified matches are significant with a significance level of $99 \%(p<0.01)$ were considered as a positive match when there are at least two unique peptides corresponding to the significance threshold with an ion score of 70; c Number of matched peptides used to identify the protein. At least one matching peptide for each identified protein must fulfill the significance criteria $(p<0.01)$ and also be unique; d Molecular weight in $\mathrm{kDa}$; e: Number of peptides matched with a threshold significance value of $p<0.05$; $f$ : The matched peptide features (area under the curve) intensity of the patients compared to the controls $\mathrm{g}$ : The statistical significance value after protein quantification data analysis. 


\begin{tabular}{|c|c|c|c|c|c|c|c|c|c|c|c|c|c|c|c|}
\hline \multirow[t]{2}{*}{ Protein Name } & \multirow[t]{2}{*}{$\begin{array}{l}\text { Gene } \\
\text { Name }\end{array}$} & \multirow[t]{2}{*}{$\begin{array}{l}\text { Uniprot } \\
\text { accession }\end{array}$} & \multirow[t]{2}{*}{$\begin{array}{l}\text { Mascot } \\
\text { Score }\end{array}$} & \multirow[t]{2}{*}{$\begin{array}{l}\text { Matched } \\
\text { peptides }\end{array}$} & \multirow[t]{2}{*}{$\begin{array}{c}\text { MW } \\
\text { d }\end{array}$} & \multirow{2}{*}{$\begin{array}{l}\text { Protein } \\
\text { sequence } \\
\text { coverage }\end{array}$} & \multicolumn{2}{|c|}{$\begin{array}{l}\text { Average area of the } \\
\text { triplicate analysis }\end{array}$} & \multirow{2}{*}{$\begin{array}{c}\text { Fold } \\
\text { Chang } \\
\text { e } \\
\text { SLE/C } \\
\text { ontrols }\end{array}$} & \multicolumn{2}{|c|}{$\begin{array}{c}\text { EmPAI } \\
\text { (Triplicates average) }\end{array}$} & \multirow{2}{*}{$\begin{array}{c}\text { EmPAI } \\
\text { Fold } \\
\text { Change }\end{array}$} & \multirow{2}{*}{$\begin{array}{c}\text { Protein } \\
\text { regulation } \\
\text { Up(+), } \\
\text { Down (-) }\end{array}$} & \multirow[t]{2}{*}{ Function } & \multirow{2}{*}{$\begin{array}{c}p- \\
\text { value } \\
\mathrm{g}\end{array}$} \\
\hline & & & & & & & SLE & Controls & & SLE & Controls & & & & \\
\hline \multicolumn{16}{|c|}{ Immunoglobulins } \\
\hline $\begin{array}{c}\text { Ig kappa chain } \\
\mathrm{C} \text { variable } \\
\text { region }\end{array}$ & IGKC & $\begin{array}{l}\text { KV315_H } \\
\text { UMAN }\end{array}$ & 212 & 77 & 12.49 & 42.7 & $\begin{array}{c}81657.3 \pm 3095 \\
1.1\end{array}$ & $\begin{array}{c}28738.8 \pm 24 \\
22.5\end{array}$ & 2.84 & $0.90 \pm 0.1$ & $\begin{array}{c}0.382 \pm 0 \\
01\end{array}$ & 2.35 & + & $\begin{array}{c}\text { Immune } \\
\text { response and } \\
\text { regulation }\end{array}$ & 0.04 \\
\hline $\begin{array}{l}\text { Ig heavy chain } \\
\text { G4 }\end{array}$ & $\begin{array}{l}\text { IGHG } \\
4\end{array}$ & $\begin{array}{l}\text { IGHG4_H } \\
\text { UMAN }\end{array}$ & 141 & 17 & 35.4 & 23.97 & $\begin{array}{c}407207.9 \pm 142 \\
838.3\end{array}$ & $\begin{array}{c}118916.6 \pm 1 \\
0435.2\end{array}$ & 3.42 & $0.72 \pm 0.1$ & $\begin{array}{c}0.29 \pm 0.0 \\
3\end{array}$ & 2.47 & + & $\begin{array}{l}\text { Immune } \\
\text { response and } \\
\text { regulation }\end{array}$ & 0.02 \\
\hline $\begin{array}{c}\text { Ig kappa } \\
\text { variable chain } \\
105\end{array}$ & $\begin{array}{l}\text { IGKV } \\
1\end{array}$ & $\begin{array}{l}\text { KV105_H } \\
\text { UMAN }\end{array}$ & 132 & 11 & 12.8 & 28.9 & $\begin{array}{c}86556.5 \pm 3253 \\
5.1\end{array}$ & $\begin{array}{c}8556.5 \pm 500 \\
3.5\end{array}$ & 10.1 & $4.51 \pm 0.23$ & $\begin{array}{c}0.27 \pm 0.0 \\
2\end{array}$ & 16.7 & + & $\begin{array}{l}\text { Immune } \\
\text { response and } \\
\text { regulation }\end{array}$ & 0.01 \\
\hline \multicolumn{16}{|c|}{ Acute phase proteins } \\
\hline Serotransferrin & $\mathrm{TF}$ & $\begin{array}{l}\text { TRFE_H } \\
\text { UMAN }\end{array}$ & 2792 & 37 & 77 & 80.8 & $\begin{array}{c}313293.8 \pm 445 \\
64.8\end{array}$ & $\begin{array}{c}134161 \pm 24 \\
375\end{array}$ & 2.3 & $3.28 \pm 0.1$ & $\begin{array}{c}1.19 \pm 0.0 \\
3\end{array}$ & 2.2 & + & $\begin{array}{c}\text { Iron } \\
\text { transport }\end{array}$ & 0.004 \\
\hline Ceruloplasmin & $\mathrm{CP}$ & $\begin{array}{l}\text { CERU_H } \\
\text { UMAN }\end{array}$ & 1093 & 26 & 122.4 & 45.2 & $\begin{array}{c}16466.94 \pm 487 \\
97.0\end{array}$ & $\begin{array}{c}45533.827 \pm \\
6382.4\end{array}$ & 3.6 & $0.37 \pm 0.03$ & $\begin{array}{c}0.16 \pm 0.0 \\
3\end{array}$ & 2.3 & + & $\begin{array}{c}\text { Iron } \\
\text { transport }\end{array}$ & 0.01 \\
\hline $\begin{array}{c}\text { Apolipoprotein } \\
\text { B }\end{array}$ & APOB & $\begin{array}{l}\text { APOB_H } \\
\text { UMAN }\end{array}$ & 345 & 13 & 515 & 35.8 & $\begin{array}{c}31774.2 \pm 1409 \\
9.0\end{array}$ & $\begin{array}{c}8020.16 \pm 93 \\
1.8\end{array}$ & 4 & $0.26 \pm 0.05$ & $\begin{array}{c}0.11 \pm 0.0 \\
1\end{array}$ & 2.4 & + & $\begin{array}{l}\text { Lipid } \\
\text { metabolism }\end{array}$ & 0.04 \\
\hline Clusterin & CLU & $\begin{array}{l}\text { CLUS_H } \\
\text { UMAN }\end{array}$ & 189 & 12 & 52.4 & 12 & $\begin{array}{c}30586.1 \pm 1288 \\
8.3\end{array}$ & $\begin{array}{c}821331121 \\
2.8 .3 \pm\end{array}$ & 0.4 & $1.15 \pm 0.06$ & $\begin{array}{c}1.74 \pm 0.2 \\
1\end{array}$ & 0.6 & - & $\begin{array}{l}\text { Innate } \\
\text { immune } \\
\text { response }\end{array}$ & 0.006 \\
\hline
\end{tabular}




\begin{tabular}{|c|c|c|c|c|c|c|c|c|c|c|c|c|c|c|c|}
\hline $\begin{array}{l}\text { Apolipoprotein } \\
\text { A1 }\end{array}$ & $\begin{array}{c}\text { APOA } \\
1\end{array}$ & $\begin{array}{l}\text { APOA1_ } \\
\text { HUMAN }\end{array}$ & 161 & 10 & 30.77 & 16 & $\begin{array}{c}59486.2 \pm 1531 \\
6.8\end{array}$ & $\begin{array}{l}122721.61 \pm \\
17765.9\end{array}$ & 0.5 & $\begin{array}{c}39.45 \pm 6.1 \\
0\end{array}$ & $\begin{array}{c}142.53 \pm 8 \\
.2\end{array}$ & 0.2 & - & $\begin{array}{l}\text { Lipid } \\
\text { transport }\end{array}$ & 0.009 \\
\hline $\begin{array}{l}\text { Apolipoprotein } \\
\text { A2 }\end{array}$ & $\begin{array}{c}\text { APOA } \\
2\end{array}$ & $\begin{array}{l}\text { APOA2 }_{-} \\
\text {HUMAN }\end{array}$ & 56 & 2 & 11.75 & 53.33 & $\begin{array}{c}41611.2 \pm 1333 \\
3.1\end{array}$ & $\begin{array}{c}67031.6 \pm 72 \\
89.8\end{array}$ & 0.6 & $43.21 \pm 5.1$ & $\begin{array}{c}213.42+ \\
9.12\end{array}$ & 0.2 & - & $\begin{array}{l}\text { Lipid } \\
\text { transport }\end{array}$ & 0.04 \\
\hline $\begin{array}{c}\text { Alpha-2- } \\
\text { macroglobulin }\end{array}$ & $\mathrm{A} 2 \mathrm{M}$ & $\begin{array}{c}\text { A2MG_H } \\
\text { UMAN }\end{array}$ & 1290 & 77 & 163.2 & 47.8 & $\begin{array}{c}6870155.6 \pm \\
1014642.0\end{array}$ & $\begin{array}{l}1812702.1 \\
\pm 203016.6\end{array}$ & 3.8 & $3.90 \pm 0.25$ & $1.33 \pm 0.1$ & 2.93 & + & $\begin{array}{l}\text { Negative } \\
\text { regulation of } \\
\text { complement } \\
\text { activation }\end{array}$ & $\begin{array}{c}0.000 \\
3\end{array}$ \\
\hline Transthyretin & TTR & $\begin{array}{c}\text { TTHY_H } \\
\text { UMAN }\end{array}$ & 526 & 81 & 15.9 & 100 & $\begin{array}{c}141897.8 \pm 328 \\
58.1\end{array}$ & $\begin{array}{c}206974.9 \pm 1 \\
3351.4\end{array}$ & 0.6 & $1.10 \pm 0.4$ & $6.22 \pm 0.3$ & 0.1 & - & $\begin{array}{c}\text { Transporting } \\
\text { thyroxine } \\
\text { and retinol }\end{array}$ & 0.03 \\
\hline \multicolumn{16}{|c|}{ Glycoproteins } \\
\hline $\begin{array}{l}\text { Alpha-1-acid } \\
\text { glycoprotein } 1\end{array}$ & ORM1 & $\begin{array}{c}\text { A1AG_H } \\
\text { UMAN }\end{array}$ & 210 & 79 & 23.51 & 23.9 & $\begin{array}{c}181401.5 \pm 705 \\
55.5\end{array}$ & $\begin{array}{c}63420.2 \pm 55 \\
6.6\end{array}$ & 2.9 & $2.27 \pm 0.44$ & $\begin{array}{c}0.950 \pm 0 . \\
03\end{array}$ & 2.3 & + & $\begin{array}{l}\text { Acute phase, } \\
\text { inflammator } \\
\text { y response }\end{array}$ & 0.04 \\
\hline $\begin{array}{l}\text { Alpha-1-acid } \\
\text { glycoprotein } 2\end{array}$ & ORM2 & $\begin{array}{l}\text { A1AG2 } \\
\text { HUMAN }\end{array}$ & 140 & 75 & 23.60 & 13 & $\begin{array}{c}145187.4 \pm 480 \\
88.9\end{array}$ & $\begin{array}{c}64026.6 \pm 37 \\
58.3\end{array}$ & 2.3 & $1.95 \pm 0.39$ & $\begin{array}{c}0.967 \pm 0 . \\
03\end{array}$ & 2.03 & + & $\begin{array}{l}\text { Acute phase } \\
\text { response, } \\
\text { inflammator } \\
\text { y response }\end{array}$ & 0.04 \\
\hline $\begin{array}{l}\text { Alpha-1-B } \\
\text { glycoprotein }\end{array}$ & A1BG & $\begin{array}{c}\text { A1BG_H } \\
\text { UMAN }\end{array}$ & 160 & 56 & 54.2 & 18 & $\begin{array}{c}74140.823134 \\
.7 \pm\end{array}$ & $\begin{array}{c}31670.2 \pm 41 \\
48.3\end{array}$ & 2.34 & $1.18 \pm 0.1$ & $\begin{array}{c}0.47 \pm 0.0 \\
4\end{array}$ & 2.5 & + & $\begin{array}{c}\text { Platelet } \\
\text { degranulatio } \\
\mathrm{n}\end{array}$ & 0.03 \\
\hline \multicolumn{16}{|c|}{ Antiproteases } \\
\hline $\begin{array}{l}\text { Alpha-1- } \\
\text { antitrypsin }\end{array}$ & $\begin{array}{l}\text { SERPI } \\
\text { NA1 }\end{array}$ & $\begin{array}{c}\text { A1AT_H } \\
\text { UMAN }\end{array}$ & 96 & 35 & 46.7 & 30.1 & $\begin{array}{c}265406.2 \pm 493 \\
73.2\end{array}$ & $\begin{array}{c}83843.4 \pm 80 \\
59.6\end{array}$ & 3.2 & $\begin{array}{c}21.41 \pm 0.7 \\
2\end{array}$ & $\begin{array}{c}5.85 \pm 0.1 \\
7\end{array}$ & 3.65 & + & $\begin{array}{c}\text { Acute phase, } \\
\text { inflammator } \\
\text { y response }\end{array}$ & 0.02 \\
\hline
\end{tabular}




\begin{tabular}{|c|c|c|c|c|c|c|c|c|c|c|c|c|c|c|c|}
\hline $\begin{array}{c}\text { Alpha-1- } \\
\text { antichymotrypsi } \\
\mathrm{n}\end{array}$ & $\begin{array}{l}\text { SERPI } \\
\text { NA3 }\end{array}$ & $\begin{array}{c}\text { AACT_H } \\
\text { UMAN }\end{array}$ & 82 & 11 & 47.6 & 30.1 & $\begin{array}{c}38590.6 \pm 1717 \\
4.4\end{array}$ & $\begin{array}{c}16122.3 \pm 16 \\
41.8\end{array}$ & 2.9 & $0.71 \pm 0.2$ & $0.57 \pm 0.3$ & 1.24 & + & $\begin{array}{c}\text { Acute phase, } \\
\text { inflammator } \\
\text { y response }\end{array}$ & 0.04 \\
\hline \multicolumn{16}{|c|}{ Binding proteins } \\
\hline Hemopexin & HPX & $\begin{array}{c}\text { HEMO_H } \\
\text { UMAN }\end{array}$ & 72 & 7 & 51.67 & 22.9 & $\begin{array}{c}29538.1 \pm 8529 \\
.0\end{array}$ & $\begin{array}{c}124043.9 \pm 9 \\
040.8\end{array}$ & 0.2 & $1.0 \pm 0.01$ & $1.7 \pm 0.1$ & 0.5 & - & $\begin{array}{c}\text { Heme } \\
\text { binding, } \\
\text { transporter } \\
\text { metabolism }\end{array}$ & 0.001 \\
\hline $\begin{array}{l}\text { Hemoglobin } \\
\text { beta subunit }\end{array}$ & HBB & $\begin{array}{c}\text { HBB_HU } \\
\text { MAN }\end{array}$ & 81 & 9 & 16 & 42.9 & $\begin{array}{c}221930.6 \pm 784 \\
25.9\end{array}$ & $\begin{array}{c}83935.03 \pm 1 \\
6376.4\end{array}$ & 2.64 & $3.27 \pm 0.2$ & $\begin{array}{c}0.90 \pm 0.0 \\
1\end{array}$ & 3.63 & + & $\begin{array}{l}\text { Heme } \\
\text { binding, } \\
\text { oxygen } \\
\text { binding }\end{array}$ & 0.04 \\
\hline Haptoglobin & HP & $\begin{array}{c}\text { HPT_HU } \\
\text { MAN }\end{array}$ & 176 & 26 & 45.2 & 30.5 & $\begin{array}{c}276225.3 \pm 895 \\
25\end{array}$ & $\begin{array}{c}121576.9 \pm 1 \\
9207\end{array}$ & 2.27 & $5.10 \pm 0.2$ & $\begin{array}{c}1.09 \pm 0.0 \\
1\end{array}$ & 2.6 & + & $\begin{array}{c}\text { Hemoglobin } \\
\text { binding }\end{array}$ & 0.04 \\
\hline
\end{tabular}


Figure 1

A representative LC-MS/MS base peak chromatograms A) SLE patients compared to B) healthy controls.

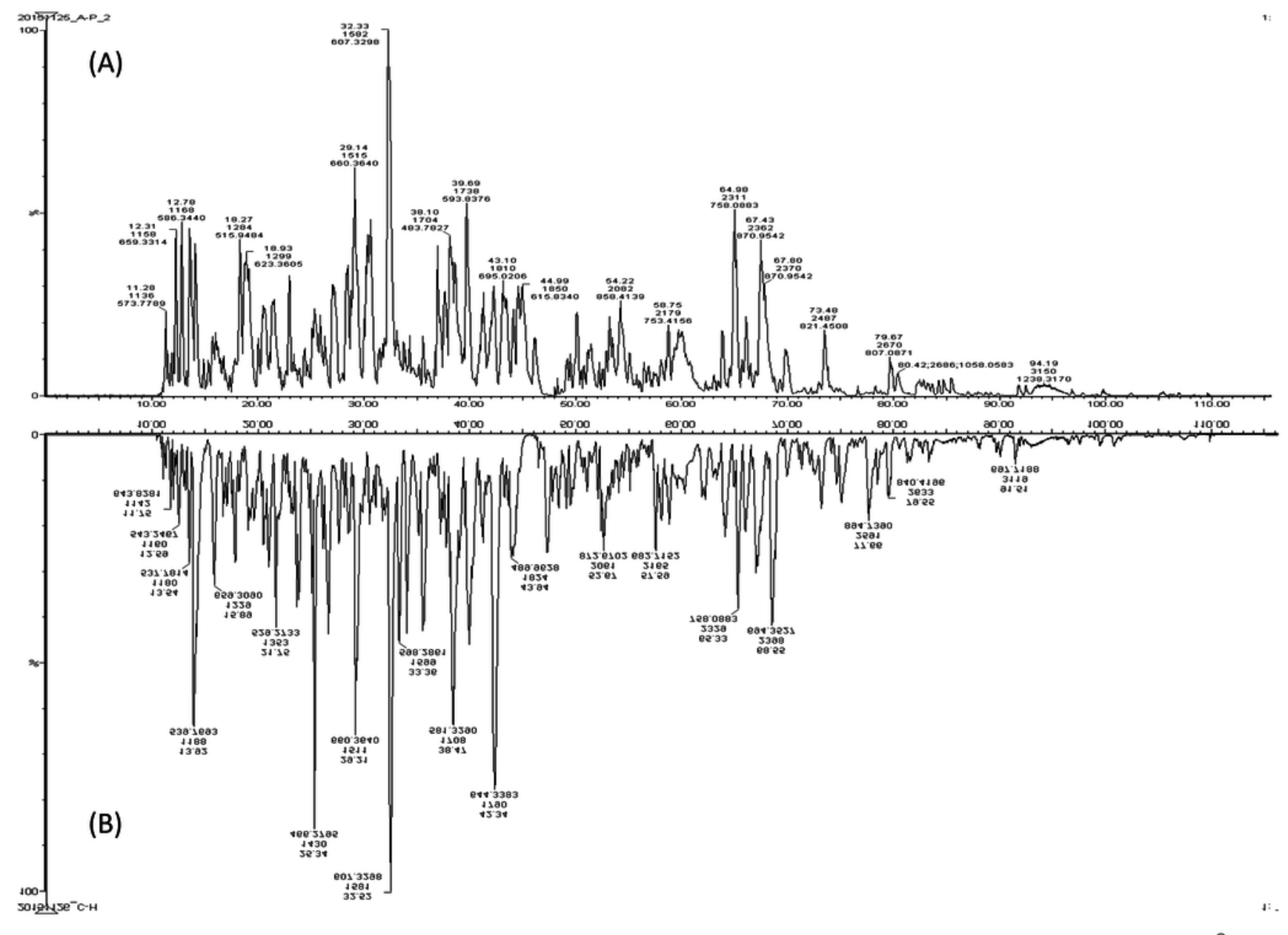




\section{Figure 2}

An overview of the plasma protein profile of the SLE patients.

The heat map was generated using PEAKS Studio 8.0 displaying the differentially expressed proteins identified using LC-MS/MS label-free proteomic analysis between SLE patients and controls. The color scale representing the relative expression level of each protein across SLE and controls; red and green color indicate the higher and lower levels of expressions. The intensity of the color represents the degree of protein up and down-regulation, when SLE patients and controls are compared.
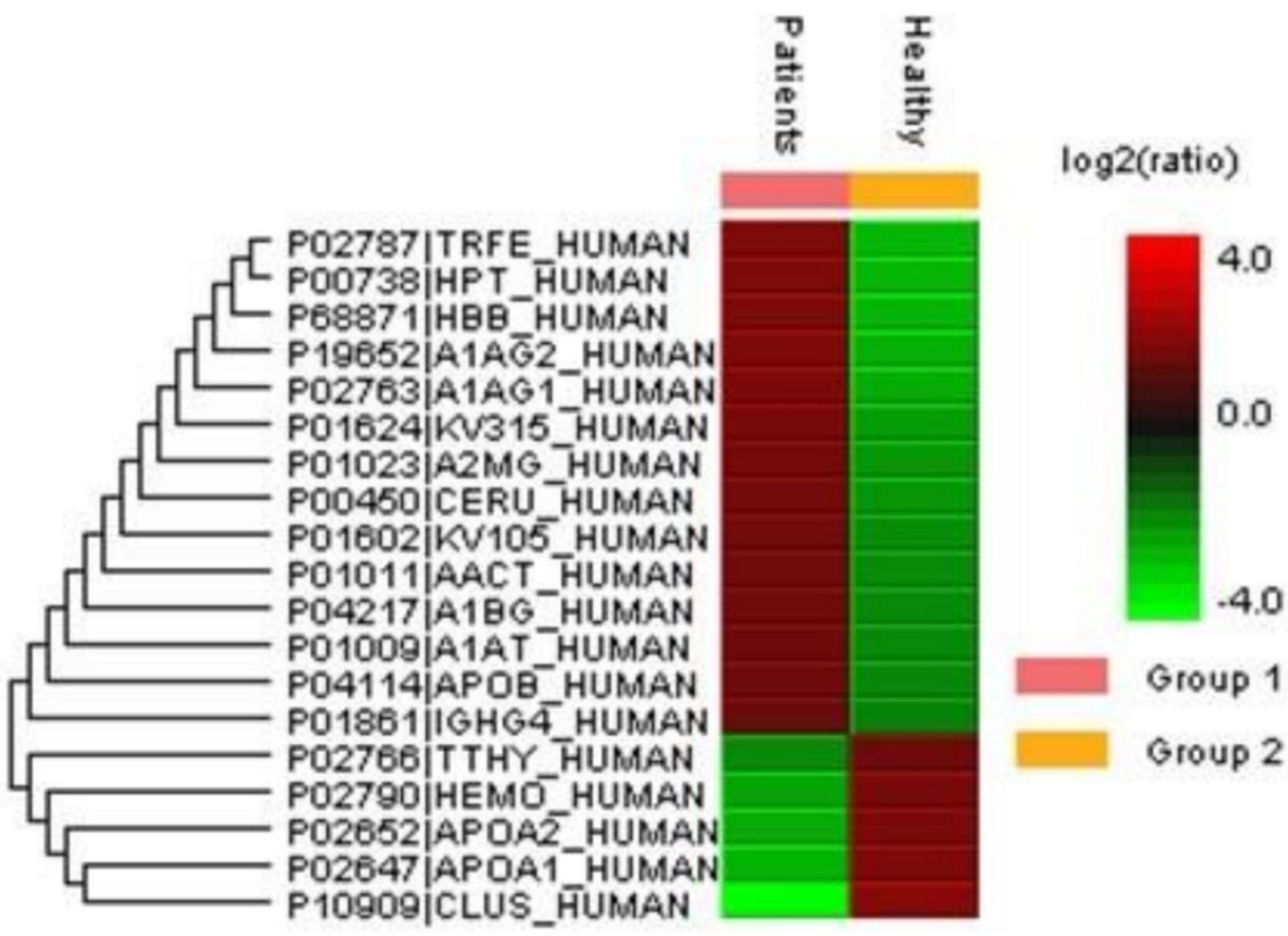


\section{Figure 3}

Gene Ontology (GO) enrichment analysis of the differentially expressed proteins.

A) Cellular component analysis of the identified proteins. B) Biological function. C) Molecular function of the identified proteins. The pie charts were generated using Panther version 11.0 released 2016-07-15.

A)

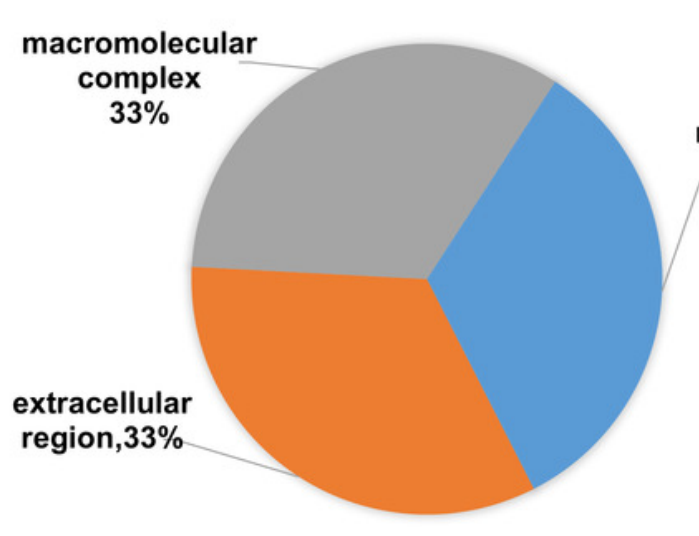

B)

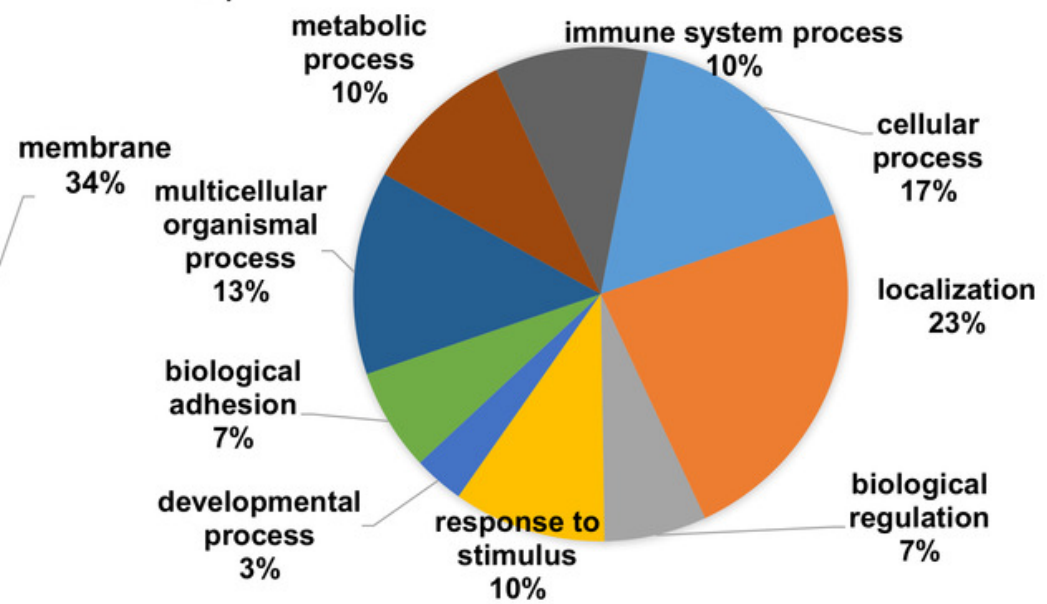

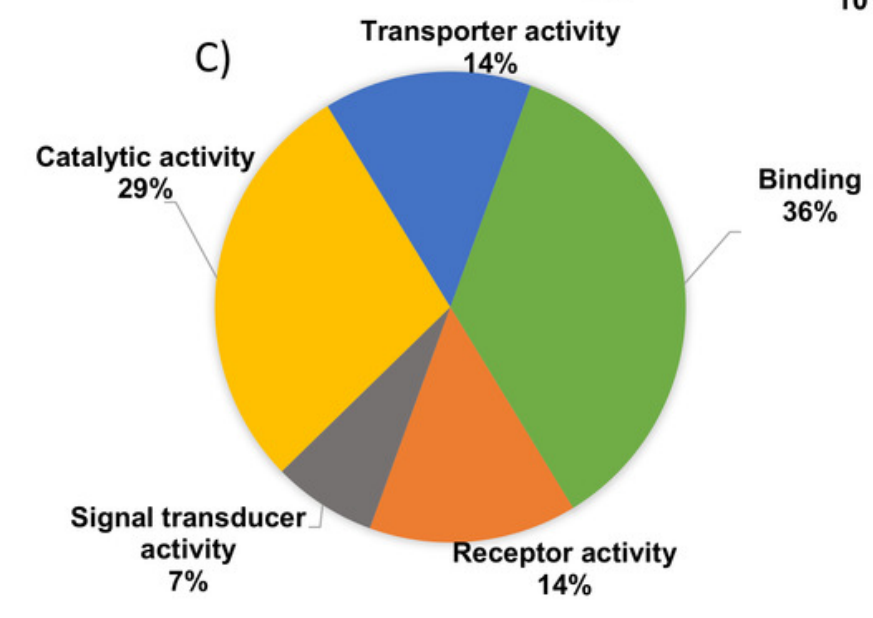




\section{Figure 4}

Kyoto encyclopedia of genes and genomes (KEGG) pathway analysis of the proteins identified as showing differential expression.

The majority of the identified proteins were enriched in relation to the complement and coagulation cascades and acute immune responses. The horizontal bars represent the number of differentially expressed proteins involved in various pathways.

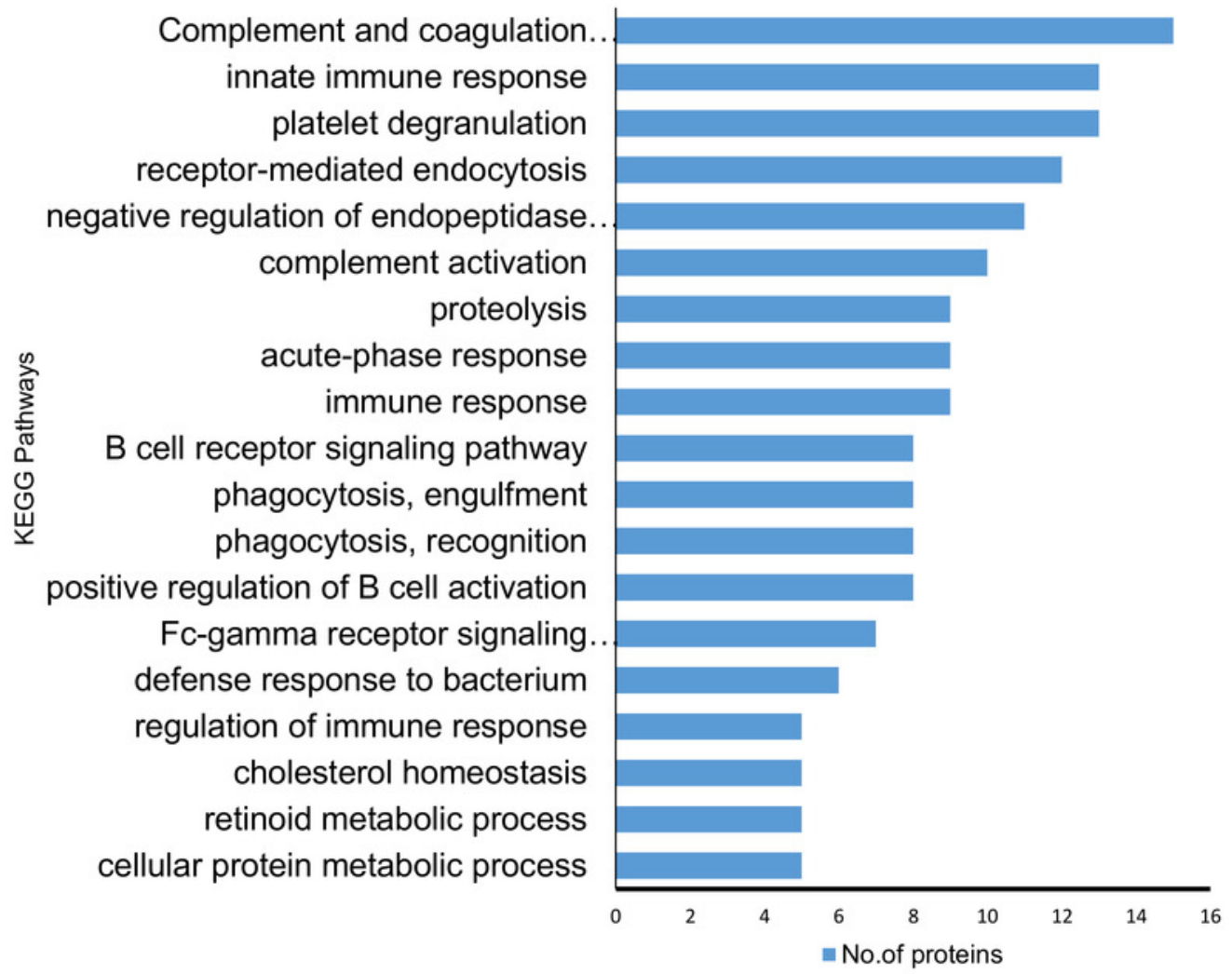


Figure 5

The protein-protein interactions for the differentially expressed proteins identified by LC-MS/MS label-free proteomics were analyzed using STRING software V9.1.

In the network analysis the differentially expressed proteins were represented as nodes.

Each color of the lines connecting the nodes indicates strong evidence of the tight network of proteins. A) The tight protein-protein interaction network obtained when the medium confidence level of 0.4 was applied. B) The high confidence (0.7) PPI network of the identified significant proteins in SLE.

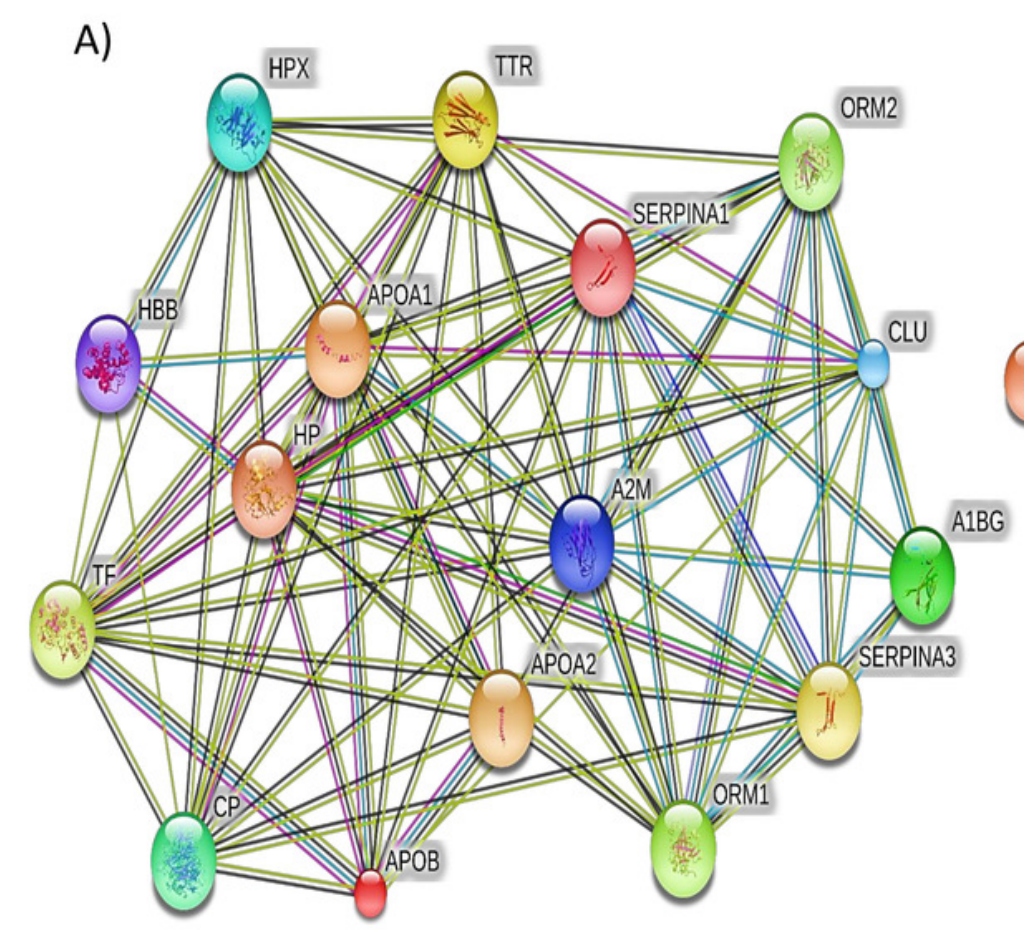

B)

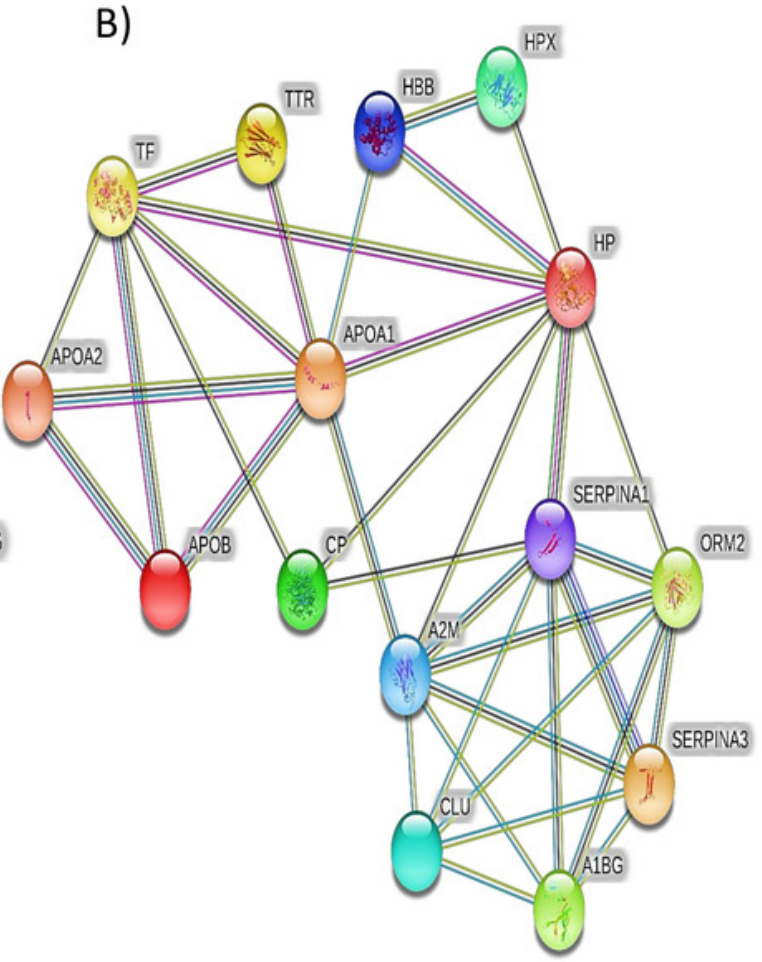

